\title{
ANÁLISE DE UMA EXPERIÊNCIA DE SUPERVISÃO NO CONTEXTO DAS POLÍTICAS SOCIAIS
}

\author{
Julia Coutinho Costa Lima* \\ Susana Carneiro Leão de Mello**
}

\section{Resumo}

Este artigo objetiva apresentar e discutir uma experiência de supervisão de equipes interdisciplinares no contexto das Políticas Sociais na atenção a crianças e adolescentes. O trabalho de supervisão desenvolvido pelas autoras deste artigo - psicólogas de orientação psicanalítica - tinha como objetivo a oferta de um espaço de escuta, reflexão e tomada de decisão acerca dos casos atendidos pelos projetos. A experiência apontou para a necessidade de uma reflexão que incluísse questóes relativas ao funcionamento da equipe, às motivações subjetivas dos profissionais, à compreensão dos objetivos e alcances do trabalho e às crenças que regulam e sustentam as intervençôes realizadas.

Palavras-chave: supervisão; cuidadores; crianças e adolescentes em risco.

\section{Abstract \\ ANALYSIS OF AN EXPERIENCE OF SUPERVISION IN THE CONTEXT OF SOCIAL POLI- CIES}

This article aims to present and discuss an experience of supervision of interdisciplinary teams in the context of Social Policies in the care of children and adolescents. The work of supervision, developed by the authors of this paper - the psychologists of psychoanalytic guidance - had as objective the provision of a space of listening, reflection and decision in concern of the cases attended by the projects. Experience pointed out the need for a reflection that included issues relating to the

* Programa de Pós-Graduação em Psicologia Cognitiva, UFPE, Pernambuco, Brasil e Círculo Psicanalítico de Pernambuco, Pernambuco, Brasil. E-mail: juliacoutinholima@gmail. com.

** Círculo Psicanalítico de Pernambuco, Pernambuco, Brasil. E-mail: susanaclmello@gmail. com. 
functioning of the team, to the subjective motivations of professionals, to the understanding of objectives and scopes of the work and beliefs that regulate and sustain the interventions.

Keywords: supervision; caregivers; children and adolescents at risk.

Durante um período de três anos, desenvolvemos um trabalho de supervisão de equipes interdisciplinares na Diretoria de Atenção Integral a crianças e adolescentes do município de Olinda/PE. Este trabalho de supervisão desenvolvido pelas autoras deste artigo - psicólogas de orientação psicanalítica - tinha por finalidade a oferta de um espaço de escuta, reflexáo e tomada de decisão acerca dos casos atendidos nos vários projetos que compunham a Política de Atenção Integral. A proposta deste artigo é discutir sobre esta experiência procurando analisar os fenômenos que se passam num processo de supervisão institucional de equipes que trabalham diretamente com situaçóes de risco e vulnerabilidade. Com isto, espera-se compartilhar os resultados de uma experiência que, apesar de particular e referente à realidade da cidade de Olinda, no nordeste do Brasil, talvez possa oferecer elementos para pensar a situação e os impasses vividos pelos profissionais habilitados para assistir crianças e jovens submetidos às condiçóes de risco e vulnerabilidade nas diferentes realidades do país.

Para contextualizar esta experiência específica de supervisão é importante destacar que este trabalho se inseria em um modelo de gestão proposto pela Diretoria de Atenção Integral à criança e ao adolescente da Secretaria de Políticas Sociais. A ideia de criar um dispositivo favorecedor da discussão dos casos atendidos surgiu em consonância com as reformulaçôes do modelo de assistência defendido pela Política Nacional de Assistência Social ${ }^{1}$.

Trata-se, portanto, de uma rede municipal de serviços integrados em que as equipes profissionais lidam diariamente com cidadãos, grupos e famílias que se encontram em situaçôes de vulnerabilidade e risco pessoal e social tais como: vivência de rua, abuso e/ou exploração sexual, trabalho infantil, abrigamento de crianças e adolescentes, situações de conflito com a lei, entre outras.

Todos estes serviços estão estruturados a partir de um Sistema Único de Assistência. Este sistema está organizado sob a égide da proteção, que visa restituir direitos aos sujeitos que estão vulneráveis e prevenir a possibilidade de riscos futuros. A proteção social envolve formas institucionalizadas de proteger indivíduos e grupos do impacto de certas vicissitudes sociais e naturais ao ciclo de vida como a velhice, as privações, infortúnio, violência. Entretanto, é importante lembrar que a história desse campo de atuação, sobretudo de suas formas institucionalizadas, esteve durante muito tempo ligada às concepçóes assistencialistas e tuteladoras. 
Quando se trata de um campo de intervenção como este se faz conveniente destacar um comentário de Matilde Luna (2001) no qual se realça a existência de uma complexa trama:

O observado, tanto em nível de análises das instituiçóes, como dos indivíduos que as operam, nos fazem entrever uma trama na qual se misturam: o controle social, o altruísmo, a beneficência, os princípios de promoção social, o desenvolvimento comunitário, o de trabalho pela integração social, etc (Luna, 2001, p. 125).

E quando esta trama se faz em torno de crianças e adolescentes parece que a lógica da proteção potencializa discursos e práticas que colocam os profissionais como agentes de salvação e mesmo da apropriação da vida dessas crianças e adolescentes. Esse tipo de contexto já levanta, por si só, questóes para serem trabalhadas num espaço de supervisão institucional.

Ao mesmo tempo, o cotidiano da atuação destes profissionais - sejam eles psicólogos, assistentes sociais, pedagogos, advogados, médicos - os leva a estarem inseridos em um contexto sócio-econômico-cultural frequentemente distinto daquele ao qual pertencem. Essa diferença de posição, que envolve diferença de pertencimento cultural, não deixa de interferir nos processos de trabalho, na relação com a comunidade atendida e na eficácia dos dispositivos oferecidos. Os desafios colocados por esse encontro de diferenças socioculturais nos atendimentos à população de baixa renda vêm sendo constantemente tematizados, tanto no que se refere às questóes colocadas para nosso aporte teórico-metodológico (Figueiredo, 2004) quanto às reflexóes sobre a necessidade de que se relativizem valores e concepçóes de subjetividade, representaçóes de saúde e doença (Costa, 1989; Bezerra Jr., 2008).

Este contexto de trabalho coloca, ainda, os profissionais frente à tarefa de lidar com padróes de relacionamento diversos daqueles que orientam habitualmente os seus pertencimentos grupais. As diferenças nos modos de compreender e vivenciar as relaçóes familiares e comunitárias podem, às vezes, criar uma sensação de "estranhamento" nos profissionais. Estranhamento ao lidar com padróes do tipo: autoridade como sinônimo de violência, pertencimento familiar como sinônimo de posse das crianças por parte dos adultos, riqueza e pobreza como sinônimo de poder e submissão. Na prática cotidiana desse tipo de trabalho, essas diferenças e "estranhamentos" frequentemente vêm à tona e têm que ser percebidos e manejados. Como afirma Bezerra Jr. (2008), ao comentar uma experiência de supervisão semelhante, o desafio consiste em construir um manejo novo e particular para cada situação. Manejo que possa incluir as singularidades do con- 
texto em questão (por exemplo, ter que lidar com a briga de gangues eclodindo dentro dos serviços) e também manejo que possa estar atento para seu papel ético e político, que busque mudança e transformação.

A isto se soma o fato de que as situaçóes tratadas - de vulnerabilidade, abandono, exclusão - são potencialmente mobilizadoras de fortes impactos emocionais nos profissionais. Um dos efeitos dessa mobilização pode ser a eclosáo de manifestaçóes de evidentes impactos afetivos, ora vivenciados como revolta e desejo de retaliaçáo, ora como profunda tristeza, apatia e falta de motivação. Sanches, Parente e Moraes (2005), ao trabalharem sobre a experiência de profissionais que atendem crianças com graves situaçóes de abandono, acrescentam que pode haver a mobilização contratransferencial da própria fantasia de abandono vivida pelos profissionais.

Foi levando em conta esta série de mobilizaçóes afetivo-emocionais que o trabalho no campo da assistência social pode provocar que se instaurou, dentro do planejamento de atividades das equipes interdisciplinares, o tempo para a fala e a reflexão sobre os casos atendidos. É interessante notar que a relevância deste tempo de supervisão, de discussão de casos é também percebida e demandada pelas equipes que trabalham nesse campo, como sublinham os artigos de Leila Torraca de Brito (2003) e de Maria Lúcia Gulassa (2006), que realizaram levantamentos com profissionais que atuam com adolescentes em conflito com a lei e com crianças abrigadas respectivamente.

Ferrari (2009), tratando sobre a experiência de supervisão institucional com equipes que trabalham com atendimento de famílias na atenção básica do SUS, corrobora a importância do espaço reservado para pensar sobre a prática, para compartilhar dúvidas, angústias e impasses que dela advêm, uma vez que as urgências e as emoções muitas vezes impedem um entendimento mais amplo dos casos atendidos:

Uma vez que o profissional náo consegue oferecer uma escuta mais ampla, numa posição empática, atento para além do que objetivamente se apresenta, atento aos movimentos contratransferenciais, às próprias resistências diante do discurso do outro, vê-se também impossibilitado de auxiliar desde um lugar de acolhimento, de reconhecimento, mas também de convocação para a vida e para o mundo (Ferrari, 2009, p. 35).

Sugere-se, ainda, que às experiências suscitadas no confronto com as realidades atendidas somam-se as questóes relativas ao contexto institucional em que o trabalho se dá. Como destaca Cavalcanti (1995), nos deparamos com a importância do espaço de fala na supervisão, sobretudo em contextos institucionais, em trabalhos que devem ser interdisciplinares: 
O espaço institucional tende a transformar-se, rapidamente, num lugar privilegiado de conflitos, que se manifestam ora pela inércia, desinvestimento e desesperança, ora por movimentos de acusaçáo, competição e inveja entre os membros da equipe. É necessário que alguém os escute para lançá-los numa outra cena, articulada em torno da problemática psíquica da criança e de suas famílias (Cavalcanti, 1995, p. 6).

Este é mais um dos aspectos a serem tratados na supervisão, as transferências cruzadas que se estabelecem entre os membros da equipe, que se somam às experiências contratransferenciais de cada profissional em relação aos indivíduos e famílias atendidos. Desse modo a supervisão se configura como um espaço de distanciamento "ótimo" que favorece a elaboração dos movimentos contratransferenciais e transferenciais envolvidos. É importante observar que a concepção aqui adotada de transferência e contratransferência não se refere à ideia de algo que atrapalha o processo e que, por isso, deve ser controlado. Ao invés disso, partilha-se da noção do campo transferencial como um plano de compartilhamento afetivo que favorece a produção de sentidos para as experiências de cada um dos parceiros (Kupermann, 2008). Assim, aposta-se que a percepçáo deste campo leva à possibilidade de implicação efetiva no agir profissional e na melhor compreensão e manejo da relação com os usuários e suas famílias.

\section{Procedimento utilizado}

O modelo de supervisão institucional que foi construído era composto por dois grupos distintos, um com os técnicos específicos de cada projeto ("supervisão de equipe"), que tinha sistemática semanal, e outro, quinzenal, que reunia técnicos de vários projetos envolvidos com o caso discutido ("supervisão entre projetos").

A condução do trabalho era feita por um profissional externo ao cotidiano do serviço, alguém que vinha de fora e que o fazia de forma sistemática, sendo, desta forma, "transformado em depositário do que acontecia nas sessóes, como se fosse um interlocutor imprescindível” (Rocha, 1997, p. 25). A opção por trabalhar com o supervisor externo aos serviços se deu para facilitar também a reflexão sobre as relaçóes e tensóes entre os profissionais que assumiam diferentes papéis junto a cada caso.

Sabe-se que a construção deste modelo de supervisão institucional se diferencia dos procedimentos tradicionais de supervisão clínica aos processos psicoterapêuticos (Zaslavsky, Nunes \& Eizirik, 2003; Saraiva \& Nunes, 2007) uma vez que não está centrado na atenção sobre as intervençôes clínicas do psicólogo, nem 
exclusivamente na relação psicoterapêutica desenvolvida, além do fato de envolver toda a equipe multiprofissional e não apenas os psicólogos. Ou seja, tratava-se de um modelo que buscava ainda favorecer o exercício da interdisciplinaridade e a aprendizagem na interação.

A experiência de supervisão aqui apresentada diferenciava-se também de outros procedimentos de inspiração psicanalítica, como as interconsultas clínicas e os grupos Balint (Kelner \& Boxwell, 1999; Kelner, 1999). Estes últimos têm em comum com o modelo tratado o fato de ressaltarem a dimensão institucional dos casos discutidos, com sua trama transferencial e contratransferencial, inclusive a que se refere à instituição. No entanto, diferentemente deste, as questóes relativas aos casos tratados em supervisão não se localizavam apenas no campo da saúde, onde a questão da doença, da morte e da hospitalização são dimensões fundamentais na discussão dos casos.

Assim, o procedimento geral nas reuniōes de supervisão com equipes tinha início com o grupo sendo convidado a apresentar os casos que gostaria de trabalhar e com a construção de uma pauta para a reunião. Na apresentação do caso eram trazidas as informaçóes e as questóes relativas ao mesmo, e todos os membros da equipe eram estimulados a expressar suas impressóes. Nesse momento se fazia possível perceber as distintas dimensōes envolvidas no caso discutido. Ainda que o objetivo central fosse a discussão dos casos propostos e dos impasses relativos aos mesmos, muitas vezes ressaltava-se a necessidade de uma reflexão mais abrangente, incluindo questóes relativas ao funcionamento da própria equipe, às suas motivaçóes subjetivas, à compreensão dos objetivos e alcances do trabalho e às crenças que regulam e sustentam as intervençóes realizadas.

\section{A supervisáo em relevo}

Para melhor percebermos esta relação entre os temas presentes nas discussôes dos casos e as questóes que emergiam no próprio grupo de profissionais se faz importante pontuar alguns aspectos.

Um primeiro deles parece sugerir uma consonância entre o tipo crença que dava sustentação às intervençôes oferecidas pelo grupo e o grau de reflexão que o mesmo se dispunha a exercitar no espaço da supervisão. Pôde-se observar, por exemplo, que a compreensão que as equipes tinham sobre os objetivos e alcances do seu trabalho e as mobilizaçóes afetivas despertadas nas diferentes situaçóes de atendimento se mostravam, na supervisão, como fatores determinantes dos alcances e da qualidade do atendimento oferecido. Enquanto que crenças de natureza altruísta sustentavam açôes "provedoras", "assistencialistas" e "compen- 
satórias", outras, baseadas na busca e promoção da autonomia, apareciam como base para a busca de alternativas mais ousadas e criativas que encorajavam os sujeitos e grupos a construírem, junto com a equipe, possibilidades e caminhos para os dilemas tratados.

Numa supervisão em que a equipe discutia um caso de três irmás que estavam afastadas de sua família por situação de abuso sexual e que mobilizava intensamente as pessoas envolvidas no atendimento, uma das técnicas da equipe se pergunta em dado momento: "A gente está se comportando como responsáveis pelas meninas? O nosso papel está confuso, até que ponto não é a gente que confunde?". Sentir-se como "os responsáveis" pelas crianças em um contexto em que os próprios pais eram acusados de maus-tratos e abuso se configurava como uma resposta quase que automática e inquestionável. $\mathrm{O}$ trabalho na supervisão possibilitava, muitas vezes, o reposicionar-se diante da situaçáo, podendo refletir desde a mobilização de um desejo de adotar aquelas crianças até aquilo que caberia ser feito em termos de cuidado e responsabilidade profissionais.

A possibilidade de se dar conta dessa "confusão de papéis" e de refletir sobre ela funcionava como uma base para as mudanças na atuação profissional e nos encaminhamentos dos casos. No entanto, nas vezes em que a reflexáo da equipe parecia movida por crenças ou comportamentos de natureza mais altruísta, o que se percebia era uma certa limitação no alcance das intervençóes realizadas. Isso pode ser ilustrado através de uma situação em que a discussão tratava sobre o desejo da equipe de poder "ofertar" alguma coisa (lanche nas reuniôes de família, cesta básica, produtos de higiene pessoal etc) às famílias atendidas pelo projeto. Tal oferta aparecia ora como um estímulo para fazer com que as famílias comparecessem às reunióes do projeto, ora como uma certa compensação, em função da situação de pobreza e miséria em que elas se encontravam. São ilustrativas desta discussão falas como: "Por trás de tudo ainda tem a sombra do não dar nada"; "Eu posso dar água? Pelo menos água!"; "A gente pode dar, pelo menos, o endereço da Vara da Justiça?". Perguntas como estas eram constantes nas discussóes e, muitas vezes, serviam como obstáculo à busca de novas saídas ou de formas mais eficazes de manejar as várias formas de demandas e solicitaçóes feitas pelos usuários atendidos.

Percebe-se aqui ainda outra questão bastante significativa: o fato de estes desejos de "ofertar" serem trazidos à tona nas reunióes de supervisão e, principalmente, o modo como eram endereçados para as supervisoras. Esse tipo de comunicação pode sinalizar um tipo de resposta transferencial vivida na relação com as supervisoras. Nesse caso, poder-se-ia perceber a tentativa de "jogar para o supervisor" o papel daquele que impede, daquele que "não facilita" as coisas, que limita. 
Outro aspecto importante, em se tratando do contexto de limitaçóes e riscos com o qual se trabalhava, diz da relaçâo entre a compreensão das equipes sobre a possibilidade de alcance do seu trabalho e a vivência dos limites e frustraçôes daí decorrentes. Num encontro em que se tratava de uma reunião de família em que nenhuma das famílias convidadas havia comparecido, foram várias as manifestaçôes de frustração e desânimo por parte da equipe: "Preparei todo o ambiente e nada. Fiquei frustrada"; "Parece que quando tudo tá organizado as coisas não acontecem”. Falas como estas podem ilustrar tanto as sensaçóes de desânimo e desinvestimento experimentadas pelas equipes quando a ação almejada não era realizada a contento quanto uma tendência para a identificação com a posição de esvaziamento e impossibilidade muitas vezes observada como marca do discurso das pessoas atendidas. No entanto, ao falar em equipe, os profissionais podiam se dar conta, juntos, destes sentimentos e então buscar reelaborá-los, voltar a investir e apostar nos resultados do trabalho.

Outras vezes os limites eram experimentados ou mesmo produzidos na própria vivência do grupo, que passava a se perceber como despossuído de recursos, de competências, não habilitado para o tipo de problemática atendida, limitado pelas circunstâncias sócio-político-econômicas. Na supervisão eram apontadas possíveis identificaçóes do funcionamento da equipe com as problemáticas tratadas. Por exemplo, em um determinado encontro, a conversa inicial do grupo versava sobre a falta de segurança sentida por todos, tanto na rua (descreviam vários assaltos sofridos) quanto na própria casa que funcionava como sede do projeto. Uma educadora conta um sonho em que um dos jovens atendidos aparecia como assassino de pessoas do grupo e uma estagiária de psicologia desabafa: "Você se sente muito fraco, muito pequenininho diante deles". Ainda em outro projeto, num momento de grande frustração diante dos fatos ocorridos, uma assistente social fala: "Estamos com a sensação de que não estamos dando conta. Os casos estão voltando, não estamos fazendo nada”. Esses são alguns exemplos de momentos em que se podia perceber uma identificação - ainda que inconsciente, num primeiro momento - da equipe com o tipo de vivência experimentada pelo público atendido. Como se os limites, a violência e a exclusão vividos pelas crianças e adolescentes acompanhados fossem também experimentados pela equipe, que se sente fraca, pequena, incapaz. Essas identificaçóes podem ser entendidas como uma forma de resposta contratransferencial do grupo, que tinha no espaço de fala livre da supervisão a oportunidade de tratar destas questôes e, assim, modificar a intervenção, possibilitando outros resultados. Compartilhar e dar-se conta destas identificaçóes funcionava como primeira etapa para transformaçóes e mudanças subjetivas. 
Quanto ao funcionamento das equipes parece ser importante exercitar o reconhecimento de conflitos e alianças que se desenvolvem entre assistentes sociais, psicólogas, pedagogas e advogados contratados. Algumas vezes estabelecia-se um conflito na equipe entre psicólogos que eram colocados - e se colocavam - como aqueles que "entendiam dos sentimentos" das crianças e os assistentes sociais que "entendiam de suas necessidades reais". Outras vezes alianças eram estabelecidas entre os membros da equipe "mais antigos" que se diferenciavam dos "recém-chegados". Tais situações podiam ser também interpretadas e trabalhadas enquanto manifestaçóes transferenciais entre os membros do grupo, entre subgrupos de técnicos de cada especialidade e mesmo na relação de cada um com os supervisores. Nas supervisóes podia haver o espaço para que esse funcionamento se expressasse, fosse reconhecido e, quando possível, modificado.

\section{Consideraçóes finais}

A partir desta experiência de supervisão institucional corrobora-se a importância reconhecida de um espaço de escuta para o profissional que lida com pessoas em situaçóes de vulnerabilidade (Ferrari, 2009; Brito, 2003). O que ainda se torna possível acrescentar é uma reflexão sobre a especificidade do enquadramento em um tipo de trabalho como este. Neste, são muitas as variáveis que ameaçam a manutenção dos pilares fundamentais que dão sustentação a esta aposta. Aposta de que é possível trabalhar com situaçóes tão difíceis e com contextos tão precários e conseguir resultados positivos tanto com o público atendido quanto com a equipe técnica.

Sobre o enquadramento da supervisão, nesse caso, é preciso que os supervisores possam encontrar estratégias para dar sustentação às demandas do grupo, sobrevivendo aos ataques de toda espécie (os de natureza institucional, como precariedade do local para realizar os encontros de supervisão, as mudanças constantes de gestão etc, e os de natureza subjetiva). Defende-se que só com a manutenção deste tipo de escuta torna-se possível que aqueles que são as dificuldades e os impasses legítimos dos profissionais possam ser comunicados, percebidos e manejados. A partir da sustentação provida pela supervisão, será possível aos profissionais a produção de novos sentidos para suas experiências, favorecendo, portanto, a manutenção da aposta nesse tipo de trabalho, manutenção do necessário campo de compartilhamento afetivo com os usuários e suas famílias.

Outra especificidade do enquadramento é a importância do supervisor externo ao serviço, de modo a propiciar a neutralidade da escuta, o trabalho com as 
transferências cruzadas dentro da equipe, bem como o lidar com as fantasias de alianças com os gestores.

Uma vez garantido esse espaço de supervisão, as próprias equipes podem usufruir deste suporte não só para dar sustentação ao trabalho que desenvolvem, mas também para propiciar e manter o reconhecimento e a identidade profissional táo necessários a este tipo de atuação.

Ao longo do trabalho de supervisão podem-se constatar mudanças e avanços nos grupos, ilustradas por fatos como um crescente sentimento de equipe e uma maior facilidade de trabalhar no contexto interdisciplinar, uma compreensão e aceitação da proposta de supervisão como um espaço de trocas e descobertas - profissionais e pessoais - e o consequente empoderamento das equipes com relação ao trabalho desenvolvido junto às crianças e adolescentes, suas famílias e os demais atores e serviços da rede.

\section{Referências}

Bezerra Jr. B. (2008). Os desafios de um experimento. In: B. Bezerra Jr. \& L. Milman (Orgs.), A casa da árvore: uma experiência inovadora na atençâo à infância (pp. 15-30). Rio de Janeiro: Garamond.

Brito, L. M. T. (2003). Encruzilhadas do sistema sócio-educativo. Psicologia Clínica, 15(1), 75-89.

Cavalcanti, A. E. (1995). A construçâo do espaço analítico institucional. Boletim de Novidades da Revista Pulsional, VIII(75), 118-132.

Costa, J. F. (1989). Psicanálise e contexto cultural. Rio de Janeiro: Campus.

Ferrari, R. (2009). Escutando famílias na rede pública: uma experiência de supervisão institucional com a equipe do PAIF - Programa de Atençấo Integral à Família do CRAS, Vinhedo, SP. Revista da SPAGESP, Sociedade de Psicoterapias Analiticas Grupais do Estado de São Paulo, $10(2), 33-40$.

Figueiredo, A. C. (2004). Vastas confusóes e atendimentos imperfeitos: a clínica psicanalitica no ambulatório público. Rio de Janeiro: Relume-Dumará.

Gulassa, M. L. C. (2006). A fala dos abrigos. In: M. V. Batista (Coord.). Abrigo: comunidade de acolhida e socioeducação (pp. 53-61). São Paulo: Instituto Camargo Corrêa.

Kelner, G. (1999). Grupos Balint. Pulsional revista de psicanálise, XII(125), 35-48.

Kelner, G. \& Boxwell, S. (1999). Interconsultas e o grupo Balint. Pulsional revista de psicanálise, $X I I(125), 7-16$.

Kupermann, D. (2008). Presença sensivel: cuidado e criação na clínica psicanalítica. Rio de Janeiro: Civilização Brasileira. 
Luna, M. (2001). Apropriação da infância vulnerável. In: L R. Castro (Org.). Crianças e jovens na construção da cultura (pp. 121-128). Rio de Janeiro: Nau Editora.

MINISTÉRIO DO DESENVOLVIMENTO SOCIAL E COMBATE À FOME. (2004). Política Nacional de Assistência Social. Brasília.

Rocha, P. S. (1997). Rumo à Ítaca (ou quinze anos depois). In: P. Rocha (Org.) Autismos (pp. 15-26). São Paulo: Escuta.

Sanches, R. M., Parente, A. M. \& Moraes, A. L. G. (2005). Psicoterapia analítica de crianças em situação de abandono: uma visão winnicottiana. In: R. M. Sanches (Org.). Winnicott na clinica e na instituição (pp. 109-132). São Paulo: Escuta.

Saraiva, L. A. \& Nunes, M. L. T. (2007). A supervisão na formação do analista e do psicoterapeuta psicanalítico. Estudos Psicologia, 12(3), 259-268.

Zaslavsky, J., Nunes, M. L. T. \& Eizirik, C. L. (2003). A supervisão psicanalítica: revisão de uma proposta de sistematização. Revista de Psiquiatria Rio Grande do Sul. Porto Alegre, 25(2), 297-309.

\section{Nota}

1 A Política Nacional de Assistência Social (2004) é um documento que objetiva oferecer parâmetros, diretrizes e estruturar a assistência social que deverá ser garantida como um direito a cidadãos e grupos que se encontram em situação de vulnerabilidade e riscos. Esse documento foi formulado dando prioridade aos princípios de: inclusão, equidade, ampliação do acesso aos bens e serviços, centralidade na família e, principalmente, uma visão social "capaz de entender que a população tem necessidades, mas também possibilidades ou capacidades que devem e podem ser desenvolvidas. Uma visão social capaz de identificar forças e não fragilidades” (p.15).

Recebido em 21 de novembro de 2011 Aceito para publicação em 10 de abril de 2012 